\title{
Addressing Stretch Myelopathy in Multilevel Cervical Kyphosis with Posterior Surgery Using Cervical Pedicle Screws
}

\author{
Bijjawara Mahesh, Bidre Upendra, Shekarappa Vijay, Kumar Arun, Reddy Srinivasa \\ Department of Spine Surgery, Jain Institute of Spine Care and Research (JISAR), Bhagwan Mahaveer Jain Hospital, Bangalore, India
}

\section{Study Design: Technique description and retrospective data analysis.}

Purpose: To describe the technique of cervical kyphosis correction with partial facetectomies and evaluate the outcome of singlestage posterior decompression and kyphosis correction in multilevel cervical myelopathy.

Overview of Literature: Kyphosis correction in multilevel cervical myelopathy involves anterior and posterior surgery. With the advent of cervical pedicle screw-rod instrumentation, single-stage posterior kyphosis correction is feasible and can address stretch myelopathy by posterior shortening.

Methods: Nine patients underwent single-stage posterior decompression and kyphosis correction for multilevel cervical myelopathy using cervical pedicle screw instrumentation from March 2011 to February 2014 and were evaluated preoperatively and postoperatively with modified Japanese Orthopaedic Association (mJOA) scoring and computed tomography scans for radiological measurements. Kyphosis assessment was made with Ishihara curvature index and C2-C7 Cobb's angle. The linear length of the spinal canal and the actual spinal canal length were also evaluated. The average follow-up was 40.56 months (range, 20 to 53 months).

Results: The average preoperative C2-7 Cobb's angle of $6.3^{\circ}\left(1^{\circ}\right.$ to $\left.12^{\circ}\right)$ improved to $2^{\circ}\left(10^{\circ}\right.$ to $\left.-9^{\circ}\right)$. Ishihara index improved from $-15.8 \%(-30.5 \%$ to $-4.7 \%)$ to $-3.66 \%(-14.5 \%$ to $+12.6 \%)$. The actual spinal canal length decreased from $83.64 \mathrm{~mm}$ (range, 76.8 to $91.82 \mathrm{~mm}$ ) to $82.68 \mathrm{~mm}$ (range, 75.85 to $90.78 \mathrm{~mm}$ ). The preoperative mJOA score of 7.8 (range, 3 to 11 ) improved to 15.0 (range, 13 to 17$)$.

Conclusions: Single-stage posterior decompression and kyphosis correction using cervical pedicle screws for multilevel cervical myelopathy may address stretch myelopathy, in addition to decompression in the transverse plane. However, cervical lordosis was not achieved with this method as predictably as by the anterior approach. The present study shows evidence of mild shortening of cervical spinal canal and a positive correlation between canal shortening and clinical improvement.

Keywords: Stretch myelopathy; Multilevel cervical myelopathy; Cervical pedicle screws; Kyphosis correction; Partial facetectomies

\section{Introduction}

The stretch component of the cervical cord seems a likely contributing factor to cervical myelopathy [1-5] apart from non-mechanical factors like ischemia, apoptosis and inflammation [3,4]. Stretch-mediated myelopathy

\footnotetext{
Received Feb 24, 2016; Revised Apr 9, 2016; Accepted Apr 9, 2016

Corresponding author: Bidre Upendra

Jain Institute of Spine care And Research (JISAR), Bhagwan Mahaveer Jain Hospital,

Vasanth Nagar, Bangalore 560052, India

Tel: +91-9686803495, Fax: +91-8022261153, E-mail: upibn75@gmail.com
} 
becomes more pronounced in a kyphotic cervical spine [6-8]. Furthermore, stretch-mediated diffuse axonal injury and the nonischemic apoptosis of oligodendroglial cells contributes to secondary spinal cord injury in tethered cord syndrome [5,9], whiplash injury and cervical spondylotic myelopathy (CSM) [10,11]. Surgical interventions planned for multilevel CSM with kyphosis need to address the stretch component on the cervical cord along with decompression in the transverse plane. Biomechanically, anterior cervical kyphosis correction with decompression over a fixed length of posterior facet joint complex may result in lengthening of the spinal canal (Fig. 1), whereas posterior compressive correction tends to decrease spinal canal length (SCL).

Kyphosis correction by the posterior approach alone requires partial facet resections and instrumented fusion under compression. However, posterior instrumentation with lateral mass screws fixation is not feasible after partial facetectomies. With the advent of cervical pedicle screw-rod instrumentation, a single-stage posterior laminectomy and kyphosis correction with partial facetectomies facilitates correction of cervical kyphosis along with decompression.

The present study was done to describe the technique of cervical kyphosis correction with partial facetectomies and to evaluate the outcome of single-stage posterior decompression and kyphosis correction in multilevel cervical myelopathy.

\section{Materials and Methods}

\section{Patients}

Nine patients undergoing single-stage posterior decompression and deformity correction for multilevel cervical myelopathy with kyphosis using cervical pedicle screw (CPS) instrumentation at our institute from March 2011 to January 2014 were included in the study. Eight patients had chronic progressive spondylotic myelopathy and the remaining patient (patient 1) had sudden onset quadriparesis with minor trauma superimposed on cervical spondylosis (Table 1). Five patients had four-level decompression and pedicle screw-rod instrumentation, three patients had three levels and one patient had five-level decompression and pedicle screw-rod instrumentation. All patients were evaluated preoperatively and postoperatively for clinical improvement using modified Japanese Orthopaedic Association (mJOA) scoring [12] and computed tomography (CT) scans were done postoperatively to assess pedicle screw placement.

\section{Kyphosis}

Radiological measurements were done to assess kyphosis using the Ishihara curvature index (1-I [13]) and C2C7 Cobb's angle preoperatively and postoperatively. Both were calculated on mid-sagittal sections of either magnetic resonance imaging (MRI) or CT scans preoperatively and postoperatively, having clear $\mathrm{C} 2-\mathrm{C} 7$ bony landmarks.

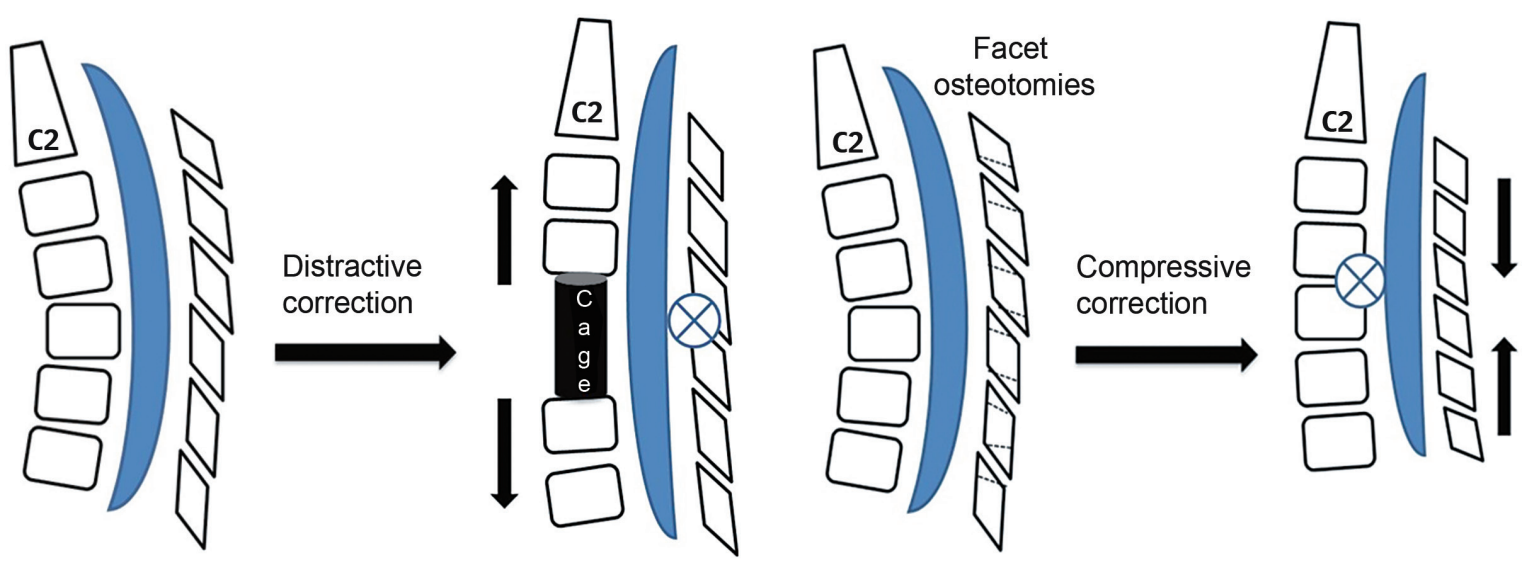

Fig. 1. The distractive correction of kyphosis achieved by anterior cage placement has a lengthening effect on the spinal cord as the axis of rotational correction falls on the fixed facet joint complex. The compressive correction achieved by partial facetectomies has a shortening effect on the spinal cord. 


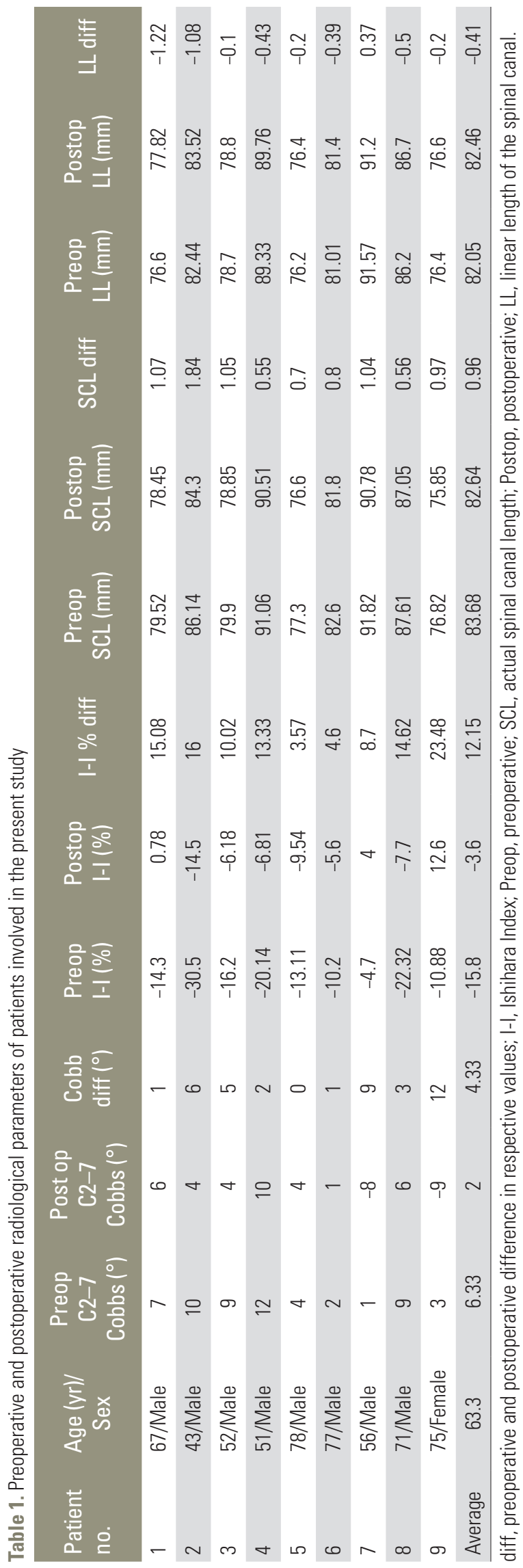

To determine the Ishihara index, the posterior inferior points of $\mathrm{C} 2$ and $\mathrm{C} 7$ were joined by a straight line denoting the linear length (LL) of the spinal canal. The transverse distance between the posterior inferior points of C3-C6 and the line LL was designated a3, a4, a5 and a6, respectively (Fig. 2). The Ishihara index was computed as $(\mathrm{a} 3+\mathrm{a} 4+\mathrm{a} 5+\mathrm{a} 6) / \mathrm{LL} \times 100$. When postero-inferior points of C3-C6 were behind the LL, the values of a3-a6 were taken as negative.

1) Cobb's angle, SCL, and LL

Cobb's angle represented the angle between the inferior endplate of C2 and the superior endplate of C7 (Fig. 2).

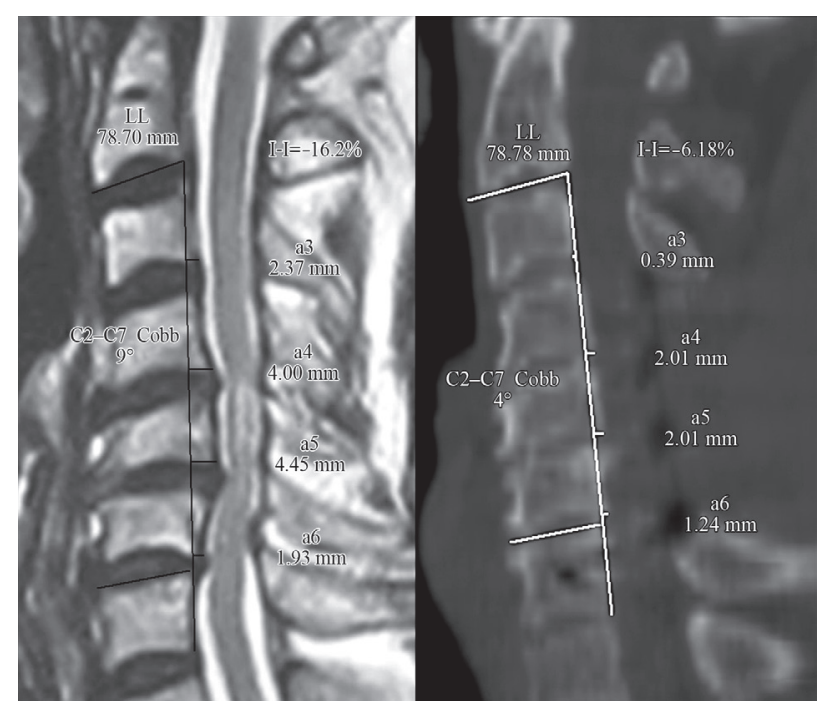

Fig. 2. Ishihara index (I-I) and C2-C7 Cobb's calculation illustrated on preoperative mid-sagittal magnetic resonance imaging and postoperative mid-saggital computed tomography scan of patient 3. LL, linear length.

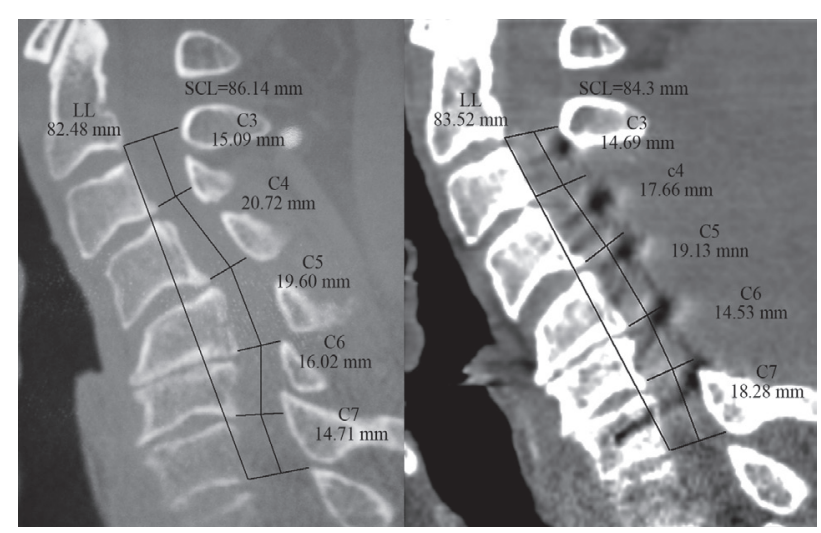

Fig. 3. Illustrates the linear length (LL) and the actual spinal canal length (SCL) being calculated in preoperative and postoperative midsagittal computed tomography scans of patient 2 . 
The SCL was determined both by linear method (LL of the spinal canal) and along the curvature of the spinal canal (actual SCL) in the mid-sagittal sections of MRI or CT scans preoperatively and postoperatively. LL was calculated by joining the posterior inferior points of $\mathrm{C} 2$ and C7 by a straight line (Fig. 3). The actual SCL was determined by lines drawn from the postero-inferior points of $\mathrm{C} 2-\mathrm{C} 7$ perpendicular to the posterior wall of the respective vertebrae up to the laminae (or extrapolated posterior canal limit in postoperative CT scans with laminectomies). The sum of the lines joining the midpoints of these lines (C3, C4, C5, C6, and C7) represented the actual SCL along the curvature of the cervical spine (Fig. 3). All measurements were made by one author (B.U.) using Surgimap spine software (Surgimap Spine-1.1.2.271 Intl. 2009, Nemaris LLC) with calibrated images of MRI and CT scans. Care was taken to match the mid-sagittal preoperative and postoperative images to avoid discrepancies in measurement.

\section{Screw placement and follow-up}

Screw placement assessment was done by evaluating pedicle screw perforations graded on axial sections of CT scans: grade I perforations had $<50 \%$ of the screw outside the pedicle and grade II perforations had $>50 \%$ of the screw outside the pedicle walls [14]. The average followup was 40.56 months (range, 20 to 53 months). Clinical complications related to CPS placement and kyphosis correction were also recorded.

\section{Surgical technique}

A midline skin incision was made and the posterior elements of the cervical vertebra to be instrumented were exposed sub-periosteally. The exposure was carried out far laterally to expose the lateral border of the lateral mass and extended cranially or caudally as required. CPS instrumentation was done at the desired levels using the medial cortical pedicle screw placement technique with partial drilling of the medial cortex, as previously described [15]. Depending on the levels of compression, laminectomies along with foraminotomies were done for central and root canal decompression. Partial facetectomies with removal of caudal edge of the superior facet and the cranial edge of the inferior facet were performed depending on the extent of kyphosis correction required.
For partial facetectomies, the medial half to two-thirds of the superior articular facet and the inferior articular facet were drilled with 3-mm cutting burr taking care to stop as the posterior cortex of the superior articular facet was reached. The thinned-out portion of the superior articular facet was removed with $2 \mathrm{~mm}$ rongers having thin foot plates over the corresponding cervical root. Most of the facet joints became mobile once the medial half to twothirds of the joint was excised and was compressed over pedicle screw-rods for kyphosis correction.

\section{Avoiding root compression}

Aggressive compression from the posterior aspect was avoided to prevent iatrogenic foraminal stenosis. After medial half-facetectomy and final compression, the space for the root was assessed by passing a blunt probe till the root exited from the foramen. Anatomically, the nerve root begins to curve ventrally after travelling the medial half of the facet (Fig. 4) and so has less chance of becoming compressed (Fig. 5). The authors preferred to keep a small portion of the lateral facet intact as it provided a bed for bone grafting for posterolateral fusion at the end of the procedure. The vertebral artery lodged anterior to the cervical root was safe and protected by the root during facetectomies. Correction of kyphosis was achieved by manual head elevation and finally by contoured rod insertion with compression as required (Fig. 5). All foramina were probed before final tightening of the screws.

\section{Statistical analysis}

Microsoft Word and Excel (Microsoft, Redmond, WA,

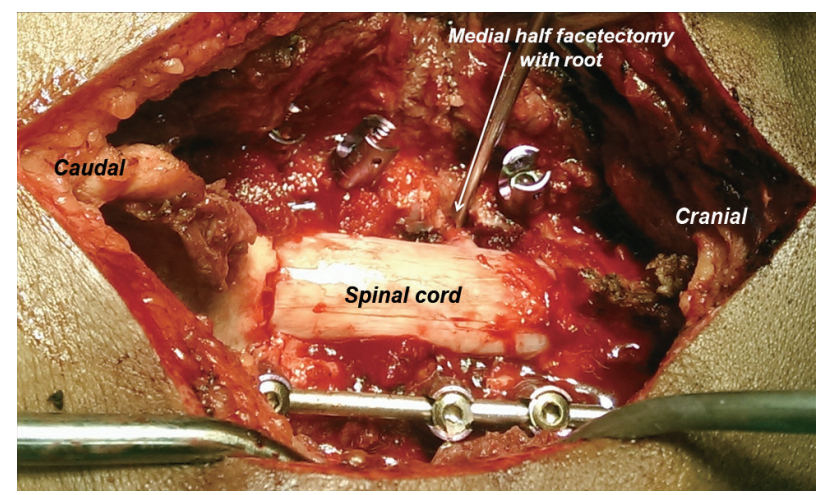

Fig. 4. Intraoperative photograph showing partial facetectomy with medial half of the facet being removed and the nerve root being visualized. 
USA) were used to generate the tabular data. Pearson's chi-square analysis was used to test bivariate relationships between outcome variables. The change in scores were computed between preoperative and postoperative measures, and bivariate relationships were determined between the changed scores (I-I, SCL, LL, Cobb, and mJOA) preoperatively and postoperatively.

\section{Results}

The average age of the nine patients ( 8 males, 1 female)

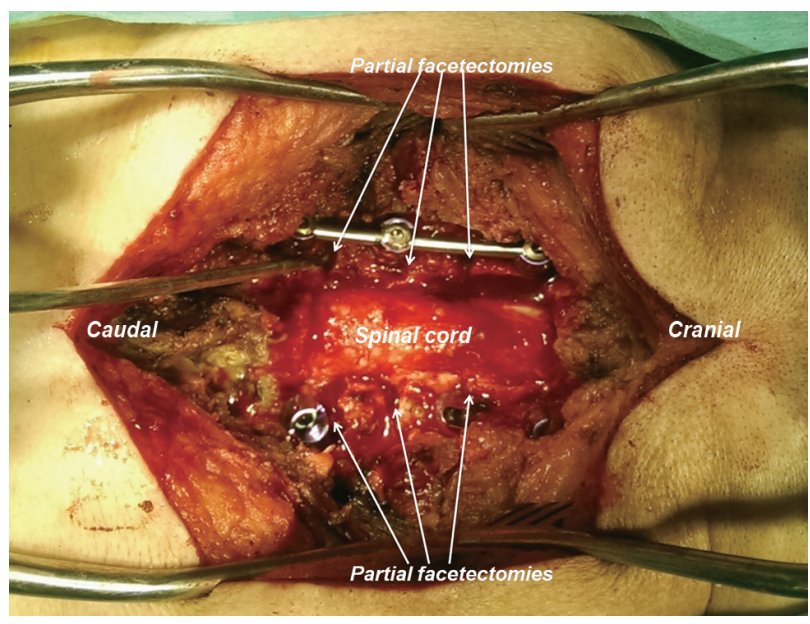

Fig. 5. Intraoperative photograph showing decompression (laminectomy with foraminotomies) with partial facetectomies and kyphosis correction using pedicle screw-rod instrumentation with compression of partial facetectomies. was 63.3 years (range, $43-78$ years). The average preoperative C2-7 Cobb's angle was $6.3^{\circ}$ kyphosis (range, $1^{\circ}$ to $12^{\circ}$ ), which marginally improved to $2^{\circ}$ (range, $10^{\circ}$ to $-9^{\circ}$ ) postoperatively. The Ishihara Index improved from $-15.8 \%$ (range, $-30.5 \%$ to $-4.7 \%$ ) to $-3.66 \%$ (range, $-14.5 \%$ to $+12.6 \%$ ) postoperatively, accounting for an average improvement of $76.8 \%$ (Table 1). The actual SCL decreased from an average of $83.64 \mathrm{~mm}$ (range, 76.8 to $91.82 \mathrm{~mm}$ ) to $82.68 \mathrm{~mm}$ (range, 75.85 to $90.78 \mathrm{~mm}$ ). LL increased postoperatively from an average of $82.0 \mathrm{~mm}$ (range, 76.2 to $91.5 \mathrm{~mm}$ ) to $82.46 \mathrm{~mm}$ (range, 76.4 to $91.2 \mathrm{~mm}$ ) (Table 1) indicating that the preoperative kyphosis was only corrected to the neutral position.

The average preoperative mJOA score of 7.88 (range, 3 to 11 ) improved to 15.0 (range, 13 to 17 ) postoperatively (Table 2). One patient (patient 2) had postoperative C5 palsy, which was improved at 8-10 weeks postoperatively. Another patient (patient 5) expired at 30-month followup due to an unrelated medical event. The average blood loss was $377 \mathrm{~mL}$ (range, 100 to $650 \mathrm{~mL}$ ) and the average operative time was 179 minutes (range, 90 to 270 minutes) (Table 2).

Sixty-one CPSs were inserted from C3-C7 with the medial cortical pedicle screw technique (Table 3) [15]. Thirty-eight screws were placed within the pedicle; 23 screws (37.7\%) showed misplacement with $13(21.3 \%)$ being grade I medial perforations. There was one grade II lateral perforation (Fig. 6) without any clinical consequences. No clinical complication directly related to screw placement

Table 2. Depicts the clinical parameters with follow-up of patients involved in the study

\begin{tabular}{lccccccccc}
$\begin{array}{l}\text { Patient } \\
\text { no. }\end{array}$ & $\begin{array}{c}\text { Age (yr)/ } \\
\text { Sex }\end{array}$ & Diagnosis & $\begin{array}{c}\text { Decomp. } \\
\text { tinst levels }\end{array}$ & $\begin{array}{c}\text { Blood loss } \\
(\mathrm{mL})\end{array}$ & $\begin{array}{c}\text { Surgical } \\
\text { time (min) }\end{array}$ & $\begin{array}{c}\text { Preop } \\
\text { mJOA }\end{array}$ & $\begin{array}{c}\text { Postop } \\
\text { mJOA }\end{array}$ & $\begin{array}{c}\text { mJOA } \\
\text { diff }\end{array}$ & $\begin{array}{c}\text { Follow-up } \\
\text { (mo) }\end{array}$ \\
\hline 1 & 67/Male & CSM & 4 & 650 & 180 & 3 & 15 & 12 & 53 \\
\hline 2 & 43/Male & CSM & 5 & 350 & 240 & 8 & 17 & 9 & 48 \\
\hline 3 & 52/Male & CSM & 4 & 250 & 120 & 11 & 16 & 5 & 36 \\
\hline 4 & 51/Male & CSM & 4 & 650 & 175 & 10 & 16 & 6 & 56 \\
\hline 5 & 78/Male & CSM & 3 & 500 & 270 & 7 & 15 & 8 & 30 \\
\hline 6 & 77/Male & CSM & 4 & 450 & 180 & 8 & 15 & 7 & 52 \\
\hline 7 & 56/Male & CSM & 3 & 250 & 180 & 9 & 13 & 4 & 48 \\
\hline 8 & $71 /$ Male & CSM & 4 & 200 & 180 & 9 & 13 & 4 & 22 \\
\hline 9 & $75 /$ Female & CSM & 3 & 100 & 90 & 6 & 15 & 9 & 20 \\
\hline Average & 63.3 & - & - & 377.7 & 179.4 & 7.88 & 15 & 7.12 & 40.56 \\
\hline
\end{tabular}

Decomp.+inst levels, number of decompression levels plus instrumentation levels; m-JOA, modified Japanese Orthopaedic Association score [12]; Preop, preoperative; SCL, actual spinal canal length; Postop, postoperative; CSM, cervical spondylotic myelopathy. 
Table 3. Shows the number of cervical pedicle screws placed in each patient along with the misplacement grades

\begin{tabular}{|c|c|c|c|c|c|c|c|c|}
\hline $\begin{array}{l}\text { Patient } \\
\text { no. }\end{array}$ & $\begin{array}{c}\text { Age }(y r) / \\
\text { Sex }\end{array}$ & Diagnosis & Level & $\begin{array}{c}\text { No. of } \\
\text { screws }\end{array}$ & $\begin{array}{l}\text { Grade-I } \\
\text { medial }\end{array}$ & $\begin{array}{c}\text { Grade-II } \\
\text { medial }\end{array}$ & $\begin{array}{l}\text { Grade-I } \\
\text { lateral }\end{array}$ & $\begin{array}{c}\text { Grade-II } \\
\text { lateral }\end{array}$ \\
\hline 1 & 67/Male & CSM & 4 & 6 & 2 & 2 & 0 & 0 \\
\hline 2 & 43/Male & CSM & 5 & 10 & 2 & 1 & 0 & 1 \\
\hline 3 & 52/Male & CSM & 4 & 8 & 1 & 1 & 1 & 0 \\
\hline 4 & 51/Male & CSM & 4 & 6 & 1 & 0 & 1 & 0 \\
\hline 5 & 78/Male & CSM & 3 & 6 & 2 & 0 & 1 & 0 \\
\hline 6 & 77/Male & CSM & 4 & 8 & 2 & 0 & 0 & 0 \\
\hline 7 & 56/Male & CSM & 3 & 5 & 1 & 0 & 1 & 0 \\
\hline 8 & 71/Male & CSM & 4 & 6 & 0 & 0 & 1 & 0 \\
\hline 9 & 75/Female & CSM & 3 & 6 & 2 & 0 & 0 & 0 \\
\hline Total & - & - & - & 61 & 13 (21.3) & $4(6.56)$ & $5(8.2)$ & $1(1.63)$ \\
\hline
\end{tabular}

Values are presented as number (\%).

CSM, cervical spondylotic myelopathy

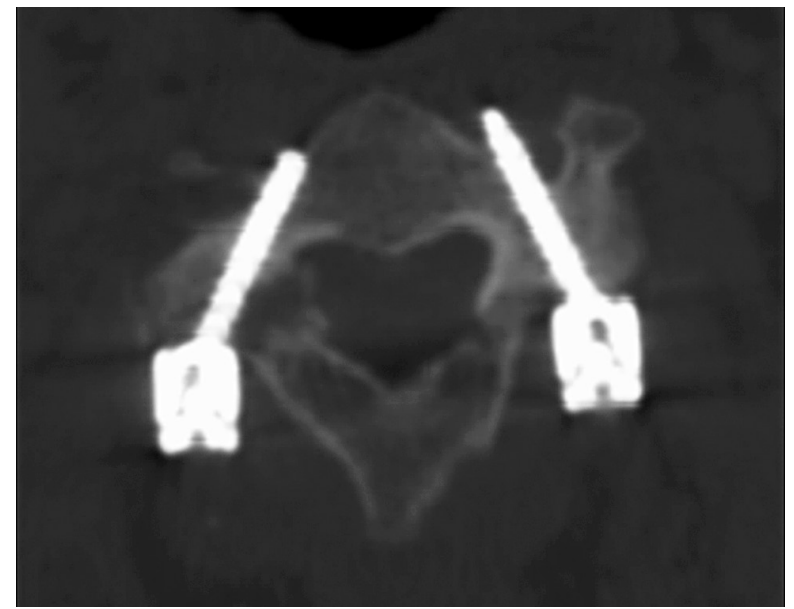

Fig. 6. A grade II lateral perforation seen at C3 vertebra (in patient 2). There were no intraoperative or postoperative complications due to the screw misplacement. The patient has completed 48-month follow-up.

was observed.

There was a significant inverse correlation $(p=0.031)$ between the LL difference with a mJOA difference following surgery $(r=-0.713)$. There were no significant bivariate relationships between Cobb, LL, and SCI change following surgery (Table 4).

\section{Discussion}

The present results indicate that the actual SCL decreases with kyphosis correction by posterior CPS instrumentation and partial facetectomies. Chiba et al. [16] reported that, despite kyphosis, laminoplasty gave good neurological recovery and avoided a planned anterior surgery in few of their patients. They reported that a decrease in the vertical height had probably contributed to neurological recovery in their patients, despite persistent kyphosis. Therefore, a decrease in SCL along with kyphosis correction is desirable. Presently there was an average decrease of $0.96 \mathrm{~mm}$ in actual SCL postoperatively (Table 1 ). SCL decrease produces slackness in the cervical cord [16]. Despite an increase in the LL of the spine, improvement in mJOA was seen in all patients. A decrease in the LL could have been achieved only if the authors were able to correct the kyphosis to lordosis, beyond the neutral alignment.

MRI studies have measured the cord length in cervical flexion, extension, and neutral position in healthy [17] and CSM [18] patients. These studies consistently reported lengthening of the cord in flexion as compared to neutral or extension. The patho-anatomical changes of the spinal cord in CSM patients [19-21] show flattening of the cord antero-posteriorly with the demyelination and gliosis that was most pronounced in the lateral portions of the cord in a cone shaped manner with the base placed laterally. These patho-anatomical findings are not consistent with the theory that antero-posterior compression is the sole primary cause of CSM [22]. Levine [22] provided evidence in a biomechanical model that the findings of lateral column involvement in CSM correlated better with the dural stretch theory. In addition, the cord is tethered to the spinal canal at points of stenosis in the cervical canal [23]. In a human cadaver study, Adams and Logue [24] 
Table 4. Statistical analysis with pearson correlation and significance of association ( $p$-value) depicted between preoperative and postoperative differences of I-I, SCL, LL, C2-C7 Cobb angle, and mJOA

\begin{tabular}{|c|c|c|c|c|}
\hline \multirow{2}{*}{ Parameters measured } & \multicolumn{4}{|c|}{ Correlation } \\
\hline & I-I diff & SCL diff & LL diff & mJOA diff \\
\hline \multicolumn{5}{|l|}{ Cobb diff } \\
\hline Pearson correlation & 0.608 & 0.375 & 0.393 & -0.131 \\
\hline Sig. (2-tailed) $p$-value & 0.082 & 0.320 & 0.296 & 0.737 \\
\hline \multicolumn{5}{|l|}{ I-I diff } \\
\hline Pearson correlation & - & 0.275 & -0.336 & 0.322 \\
\hline Sig. (2-tailed) $p$-value & - & 0.474 & 0.376 & 0.399 \\
\hline \multicolumn{5}{|l|}{ SCL diff } \\
\hline Pearson correlation & - & - & -0.393 & 0.392 \\
\hline Sig. (2-tailed) $p$-value & - & - & 0.295 & 0.297 \\
\hline \multicolumn{5}{|l|}{ LL diff } \\
\hline Pearson correlation & - & - & - & -0.713 \\
\hline Sig. (2-tailed) $p$-value & - & - & - & 0.031 \\
\hline
\end{tabular}

I-I, Ishihara Index; SCL, actual spinal canal length; LL, linear length of the spinal canal; mJOA, modified Japanese Orthopaedic Association score; diff, preoperative and postoperative difference in respective values; Sig., significance.

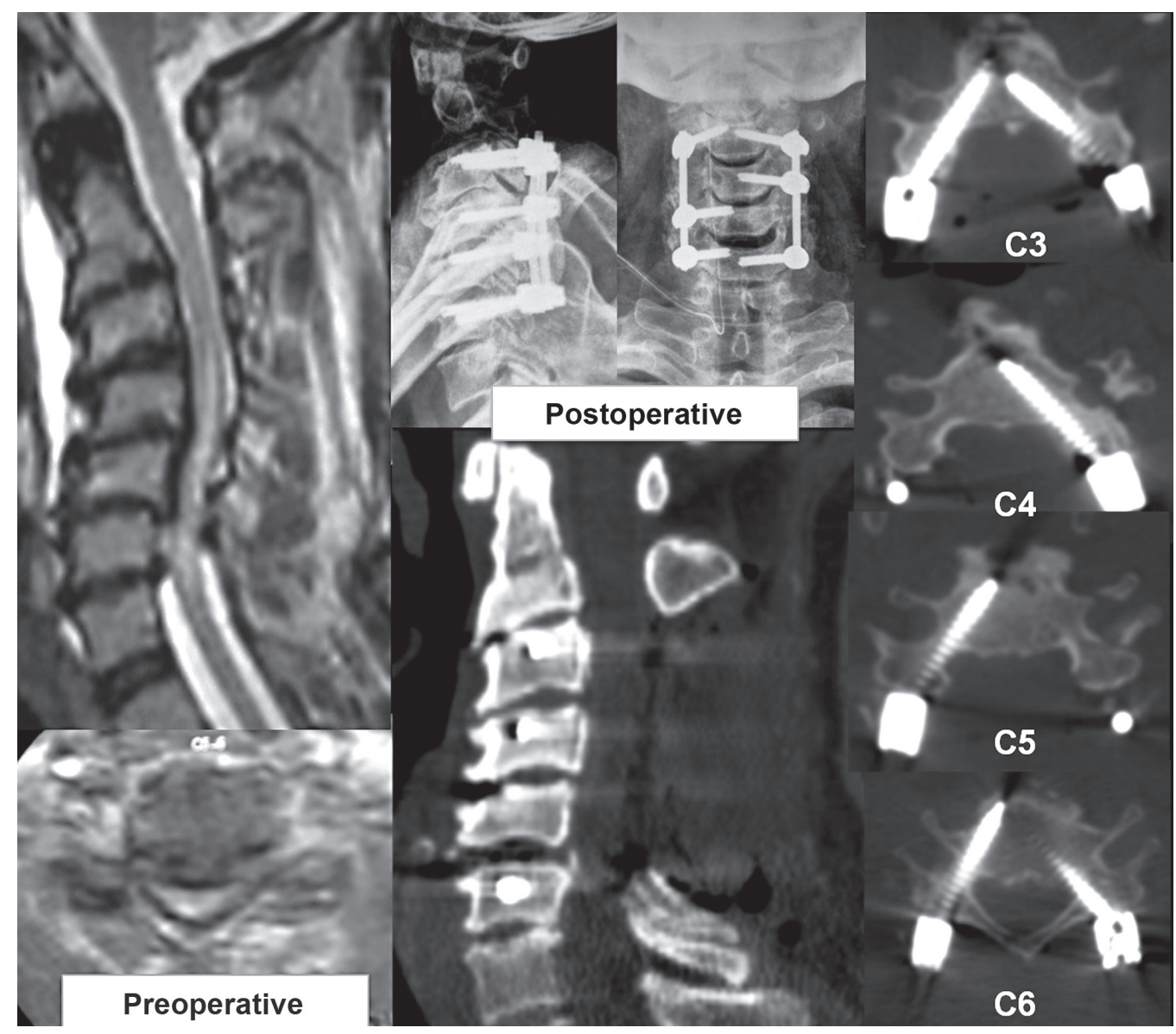

Fig. 7. Examinations of patient 1 reveals the preoperative kyphotic cervical stenosis with intra-medullary signal changes on magnetic resonance imaging and postoperative X-ray and computed tomography scans. Note the effect of partial drilling of the medial cortex with increased tendency of medial perforations by the screws [15]. 
described the localized increase in dural stretch adjacent to the point of dural fixation by stenotic segments.

Two illustrative cases are described. Patient 1 (Fig. 7) was a 67 -year-old male with sudden onset quadriparesis due to a fall 1 week before admission. He had cervical kyphosis with multilevel compressive myelopathy and was operated on using single-stage laminectomy and CPS rod instrumentation from $\mathrm{C} 3-\mathrm{C} 6$ with deformity correction by partial facetectomies. He recovered well and has completed 53 months of follow-up, and is at present ambulatory without support. His preoperative mJOA of 3 has improved to 15 . Patient 2 (Fig. 8) is 43 -year-old male who presented with progressive spasticity in lower limbs for 6 months and inability to walk since 1 month before admission. His imaging showed a sigmoid cervical kyphotic deformity with myelopathic cord changes. He underwent posterior laminectomies with partial facetectomies for decompression and deformity correction by CPS instrumentation. He developed unilateral C5 palsy postoperatively, which gradually improved by $8-12$ weeks.
He has completed 48 months of follow-up and is gainfully employed with ability to do all his indoor and outdoor activities without any support. His preoperative mJOA of 8 has improved to 17.

The largest study of cervical kyphosis correction with CPS instrumentation comprising of thirty patients was reported by Abumi et al. [25]. There were only four patients with CSM in their series (Table 5). One of the reasons for very few studies [25-28] on kyphosis correction with CPS instrumentation in CSM is the relatively high incidence of CPS misplacements in CSM patients as compared to other pathologies. The perforation rates are reported to be about $37.5 \%$ [29]. Furthermore, the numbers of lateral perforations are reportedly twice that of medial perforations. In the present study, although the authors experienced a misplacement rate of $37.7 \%$, most were grade I medial perforations $(21.3 \%)$, and $9.83 \%$ ( $8.2 \%$ grade I; $1.63 \%$ grade II) had lateral perforations (Table 3). A multicenter study [14] on CPS complications reported $75 \%$ of CPS perforations were lateral perforations endangering the vertebral artery,

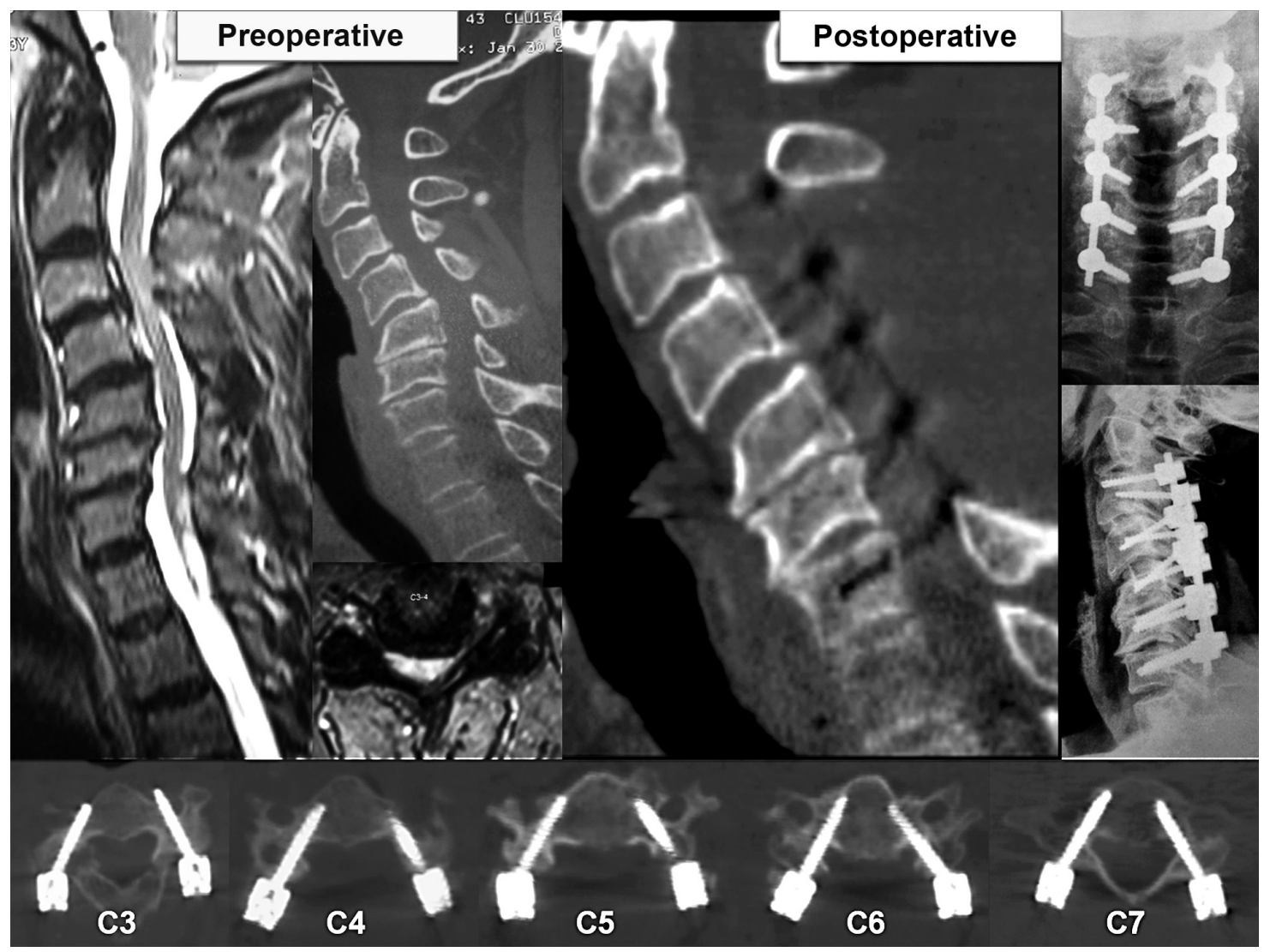

Fig. 8. Examinations of patient 2 shows preoperative sigmoid kyphotic cervical spine on magnetic resonance imaging and computed tomography (CT) scans, and postoperative X-ray and CT scans along with axial sections showing placement of pedicle screws at each level. 
Table 5. Comparison of studies evaluating results of decompression, posterior instrumentation, and kyphosis correction in multilevel cervical spondylotic myelopathy

\begin{tabular}{|c|c|c|c|c|c|}
\hline Study, year & $\begin{array}{l}\text { No. of patients } \\
\text { (CSM) }\end{array}$ & $\begin{array}{l}\text { Surgery and } \\
\text { fixation }\end{array}$ & $\begin{array}{l}\text { Ishihara curvature } \\
\text { index or kyphosis } \\
\text { improvement }\end{array}$ & $\begin{array}{c}\text { Neurology/JOA } \\
\text { scores } \\
\text { improvement }\end{array}$ & $\begin{array}{l}\text { Actual spinal } \\
\text { canal length } \\
\text { shortening }\end{array}$ \\
\hline $\begin{array}{l}\text { Abumi et al. [25], } \\
1999\end{array}$ & $\begin{array}{l}30 \text { (4 with } \\
\text { CSM)+cervical } \\
\text { kyphosis }\end{array}$ & $\begin{array}{l}\text { CPS with laminectomy } \\
\text { and partial } \\
\text { facetectomies }\end{array}$ & $24^{\circ}\left(28.4^{\circ}\right.$ to $\left.4.4^{\circ}\right)$ & $\begin{array}{l}1-2 \text { grade improvement } \\
\text { in Frankle grade }\end{array}$ & Not evaluated \\
\hline Du et al. [26], 2014 & 43 (21 with CSM) & $\begin{array}{l}\text { Lateral mass } \\
\text { fixation+laminectomy }\end{array}$ & $\begin{array}{l}10.9 \%(+8.4 \% \text { to } \\
+19.3 \%)\end{array}$ & $8.7(6.2$ to 14.9$) \mathrm{mJOA}$ & Not evaluated \\
\hline $\begin{array}{l}\text { Uehara et al. [27], } \\
2012\end{array}$ & $\begin{array}{l}13 \text { CSM+ segmental } \\
\text { instability }\end{array}$ & $\begin{array}{l}\text { CPS } \\
\text { (CAS)+laminoplasty }\end{array}$ & Not evaluated & 3.5 (9.1 to 12.6$) \mathrm{mJOA}$ & Not evaluated \\
\hline $\begin{array}{l}\text { Kotil and Ozyuvaci } \\
\text { [28], } 2011\end{array}$ & 10 CSM+kyphosis & CPS+laminectomy & $\begin{array}{l}24.2^{\circ}\left(23^{\circ} \text { kyphosis }\right. \\
\text { to } 1.2^{\circ} \text { lordosis) }\end{array}$ & $\begin{array}{l}90 \% \text { had nurick } \\
\text { grade improvement } \\
\text { (not specified) }\end{array}$ & Not evaluated \\
\hline Present study & $\begin{array}{l}9 \text { CSM+cervical } \\
\text { kyphosis }\end{array}$ & $\begin{array}{l}\text { CPS with laminectomy } \\
\text { and partial } \\
\text { facetectomies }\end{array}$ & $\begin{array}{l}12.15 \% \\
(-15.8 \% \text { to }-3.66 \%)\end{array}$ & $\begin{array}{l}7.12(7.88 \text { to } 15.0) \\
\text { mJOA }\end{array}$ & $\begin{array}{l}0.96 \mathrm{~mm} \\
\text { (83.64 to 82.68) }\end{array}$ \\
\hline
\end{tabular}

CSM, cervical spondylotic myelopathy; JOA, Japanese Orthopaedic Association score; CPS, cervical pedicle screws; mJOA, modified Japanese Orthopaedic Association score [12]; CAS, computer assisted surgery.

in contrast to our results of more medial perforations. This further substantiates the previous report [15] on the decreased lateral perforation rates seen with the medial cortical pedicle screw insertion technique.

Surgical management of multilevel CSM with kyphosis has been challenging with the literature showing no single approach to be superior. An anterior-only approach with multilevel corpectomy has been fraught with early mechanical failures with graft and implant dislodgement [30,31]. A combined anterior and posterior procedure has been found to decrease the mechanical failures with good fusion rates and neurological outcome [32]. Wen et al. [33] compared the efficacy of anterior-posterior combined surgery with anterior or posterior alone surgeries in a 255 patient series. Kyphosis correction was better with anterior procedures, but was complicated by implant failures in multilevel decompressions. The combined procedure yielded the best results with good kyphosis correction, neurological recovery and reduced mechanical failures due to rigid fixation, but with increased morbidity of the combined procedure. In this context, posterior alone surgery with CPS is an additional alternative in patients with multilevel CSM with kyphosis, for better kyphosis correction with more aggressive facetectomies and rigid internal fixation, avoiding a combined approach in the elderly.

The present study is limited due to the small number of patients and its retrospective design. However, this needs to be seen in the context of the largest series of cervical kyphosis correction (30 patients) using CPS [25], which included only four patients with CSM. The present study involves measurements made on mid-sagittal sections of preoperative and postoperative MRI or CT scans. All the measurements were made by a single author, who was also involved in the surgery, which could have led to bias in these measurements.

The present study brings to the forefront the concept of surgically addressing stretch myelopathy, which has not received much attention in surgical management of multilevel CSM with kyphosis. This study provides evidence of shortening, albeit minimal, of the cervical spinal canal, with posterior deformity correction using CPS. It also shows a positive correlation between canal shortening and clinical improvement (mJOA), which might be partially due to decompression alone. Either anterior or posterior decompressive surgery provides predictable neurological recovery irrespective of the amount of kyphosis correction [34]. However, long-term results of persistent kyphosis are not encouraging with progression of deformity and deterioration of neurology [35]. Further, it is not yet clear if kyphosis correction and shortening of the SCL has any reversible effect on the stretch mediated axonal and myelin changes in the cervical spinal cord. 


\section{Conclusions}

Single-stage posterior decompression and kyphosis correction using CPSs for multilevel cervical myelopathy with kyphosis may address the stretch component on the spinal cord in addition to decompression in the transverse plane. However, cervical lordosis was not achieved with this method, as predictably as by the anterior approach. Further studies are required to ascertain the reproducibility of spinal canal shortening by posterior kyphosis correction using CPS and to evaluate any reversible effects on the stretch mediated axonal and myelin changes in the cervical spinal cord.

\section{Conflict of Interest}

No potential conflict of interest relevant to this article was reported.

\section{References}

1. Karadimas SK, Gatzounis G, Fehlings MG. Pathobiology of cervical spondylotic myelopathy. Eur Spine J 2015;24 Suppl 2:132-8.

2. Kalsi-Ryan S, Karadimas SK, Fehlings MG. Cervical spondylotic myelopathy: the clinical phenomenon and the current pathobiology of an increasingly prevalent and devastating disorder. Neuroscientist 2013; 19:409-21.

3. Karadimas SK, Erwin WM, Ely CG, Dettori JR, Fehlings MG. Pathophysiology and natural history of cervical spondylotic myelopathy. Spine (Phila Pa 1976) 2013;38(22 Suppl 1):S21-36.

4. Fehlings MG, Skaf G. A review of the pathophysiology of cervical spondylotic myelopathy with insights for potential novel mechanisms drawn from traumatic spinal cord injury. Spine (Phila Pa 1976) 1998; 23:2730-7.

5. Henderson FC, Geddes JF, Vaccaro AR, Woodard E, Berry KJ, Benzel EC. Stretch-associated injury in cervical spondylotic myelopathy: new concept and review. Neurosurgery 2005;56:1101-13.

6. Snow RB, Weiner H. Cervical laminectomy and foraminotomy as surgical treatment of cervical spondylosis: a follow-up study with analysis of failures. J Spinal Disord 1993;6:245-50.

7. Sim FH, Svien HJ, Bickel WH, Janes JM. Swan-neck deformity following extensive cervical laminectomy. A review of twenty-one cases. J Bone Joint Surg Am 1974;56:564-80.

8. Breig A, Turnbull I, Hassler O. Effects of mechanical stresses on the spinal cord in cervical spondylosis. A study on fresh cadaver material. J Neurosurg 1966;25: 45-56.

9. Breig A. Overstretching of and circumscribed pathological tension in the spinal cord: a basic cause of symptoms in cord disorders. J Biomech 1970;3:7-9.

10. Yamaura I, Yone K, Nakahara S, et al. Mechanism of destructive pathologic changes in the spinal cord under chronic mechanical compression. Spine (Phila Pa 1976) 2002;27:21-6.

11. Li GL, Brodin G, Farooque M, et al. Apoptosis and expression of Bcl-2 after compression trauma to rat spinal cord. J Neuropathol Exp Neurol 1996;55:2809.

12. Kopjar B, Tetreault L, Kalsi-Ryan S, Fehlings M. Psychometric properties of the modified Japanese Orthopaedic Association scale in patients with cervical spondylotic myelopathy. Spine (Phila Pa 1976) 2015; 40:E23-8.

13. Ohara A, Miyamoto K, Naganawa T, Matsumoto K, Shimizu K. Reliabilities of and correlations among five standard methods of assessing the sagittal alignment of the cervical spine. Spine (Phila Pa 1976) 2006;31:2585-91.

14. Nakashima H, Yukawa Y, Imagama S, et al. Complications of cervical pedicle screw fixation for nontraumatic lesions: a multicenter study of 84 patients. J Neurosurg Spine 2012;16:238-47.

15. Mahesh B, Upendra B, Mahan RS. The medial cortical pedicle screw: a new technique for cervical pedicle screw placement with partial drilling of medial cortex. Spine J 2014;14:371-80.

16. Chiba K, Toyama Y, Watanabe M, Maruiwa H, Matsumoto M, Hirabayashi K. Impact of longitudinal distance of the cervical spine on the results of expansive open-door laminoplasty. Spine (Phila Pa 1976) 2000;25:2893-8.

17. Kuwazawa Y, Pope MH, Bashir W, Takahashi K, Smith FW. The length of the cervical cord: effects of postural changes in healthy volunteers using positional magnetic resonance imaging. Spine (Phila $\mathrm{Pa}$ 1976) 2006;31:E579-83.

18. Zhang L, Zeitoun D, Rangel A, Lazennec JY, Catonne 
Y, Pascal-Moussellard H. Preoperative evaluation of the cervical spondylotic myelopathy with flexionextension magnetic resonance imaging: about a prospective study of fifty patients. Spine (Phila Pa 1976) 2011;36:E1134-9.

19. Brain WR, Northfield D, Wilkinson M. The neurological manifestations of cervical spondylosis. Brain 1952;75:187-225.

20. Mair WG, Druckman R. The pathology of spinal cord lesions and their relation to the clinical features in protrusion of cervical intervertebral discs; a report of four cases. Brain 1953;76:70-91.

21. Ogino H, Tada K, Okada K, et al. Canal diameter, anteroposterior compression ratio, and spondylotic myelopathy of the cervical spine. Spine (Phila Pa 1976) 1983;8:1-15.

22. Levine DN. Pathogenesis of cervical spondylotic myelopathy. J Neurol Neurosurg Psychiatry 1997;62:33440.

23. Tencer AF, Allen BL Jr, Ferguson RL. A biomechanical study of thoracolumbar spine fractures with bone in the canal. Part III. Mechanical properties of the dura and its tethering ligaments. Spine (Phila $\mathrm{Pa}$ 1976) $1985 ; 10: 741-7$.

24. Adams CB, Logue V. Studies in cervical spondylotic myelopathy. I. Movement of the cervical roots, dura and cord, and their relation to the course of the extrathecal roots. Brain 1971;94:557-68.

25. Abumi K, Shono Y, Taneichi H, Ito M, Kaneda K. Correction of cervical kyphosis using pedicle screw fixation systems. Spine (Phila Pa 1976) 1999;24:238996.

26. Du W, Zhang P, Shen Y, Zhang YZ, Ding WY, Ren LX. Enlarged laminectomy and lateral mass screw fixation for multilevel cervical degenerative myelopathy associated with kyphosis. Spine J 2014;14:57-64.

27. Uehara M, Takahashi J, Ogihara N, et al. Cervical pedicle screw fixation combined with laminoplasty for cervical spondylotic myelopathy with instability. Asian Spine J 2012;6:241-8.

28. Kotil K, Ozyuvaci E. Multilevel decompressive laminectomy and transpedicular instrumented fusion for cervical spondylotic radiculopathy and myelopathy: a minimum follow-up of 3 years. J Craniovertebr Junction Spine 2011;2:27-31.

29. Uehara M, Takahashi J, Hirabayashi H, et al. Perforation rates of cervical pedicle screw insertion by disease and vertebral level. Open Orthop J 2010;4:142-6.

30. Sasso RC, Ruggiero RA Jr, Reilly TM, Hall PV. Early reconstruction failures after multilevel cervical corpectomy. Spine (Phila Pa 1976) 2003;28:140-2.

31. Zdeblick TA, Hughes SS, Riew KD, Bohlman HH. Failed anterior cervical discectomy and arthrodesis. Analysis and treatment of thirty-five patients. J Bone Joint Surg Am 1997;79:523-32.

32. Kim PK, Alexander JT. Indications for circumferential surgery for cervical spondylotic myelopathy. Spine J 2006;6:299S-307S.

33. Wen SF, Wong IO, Long MJ, et al. Effectiveness of 3 surgical decompression strategies for treatment of multilevel cervical myelopathy in 3 spinal centers in China: a retrospective study. Spine (Phila Pa 1976) 2012;37:1463-9.

34. Kawakami M, Tamaki T, Ando M, Yamada H, Yoshida M. Relationships between sagittal alignment of the cervical spine and morphology of the spinal cord and clinical outcomes in patients with cervical spondylotic myelopathy treated with expansive laminoplasty. J Spinal Disord Tech 2002;15:391-7.

35. Suda K, Abumi K, Ito M, Shono Y, Kaneda K, Fujiya M. Local kyphosis reduces surgical outcomes of expansive open-door laminoplasty for cervical spondylotic myelopathy. Spine (Phila Pa 1976) 2003;28:125862. 